\title{
Analisis pendapatan pekerja sektor informal disekitar objek wisata jembatan pendestrian kawasan objek wisata menara Gentala Arasy Kota Jambi
}

\author{
M. Syahdan Fathiri *; Zulfanetti \\ Prodi Ekonomi Pembangunan Fak.Ekonomi dan Binsis Universitas Jambi \\ *E-mail korespondensi: syahdanfathiri1997@gmail.com
}

\begin{abstract}
The purpose of this study was to determine the socio-economic characteristics of traders around the tourist attraction of the pedestrian bridge, to determine the potential and strategies of tourism development, and to determine differences in income from the informal sector. The data used in this study is primary data consisting of interview data. The method used for this research is a field research method with observation techniques and conducting interviews, and distributing questionnaires. The results showed that the variables of age, amount of savings, number of dependents, transportation expenses, and number of tourist visits had a significant effect. However, partially the number of dependents and the number of tourist visits significantly affect the income of informal sector workers around the Pedestrian Bridge Tourism Object in the Gentala Arasy Tower Tourism Object, Jambi City.
\end{abstract}

Keywords: Income, Informal sector workers, Tourist attraction

\begin{abstract}
Abstrak
Tujuan penelitian ini adalah mengetahui karateristik sosial ekonomi pedagang disekitar objek wisata jembatan pendestrian, mengetahui potensi dan strategi pengembangan pariwisatan dan untuk mengetahui perbedaan pendapatan sektor informal. Data yang digunkan dalam penelitian adalah data primer yang terdiri dari data wawancara. Metode yang digunakan untuk penelitian ini adalah metode penelitian lapangan dengan teknik observasi dan melakukan wawancara maupun penyebaran kuisioner. Metode analisis data menggunakan analisis regresi linear berganda. Hasil penelitian menunjukkan bahwa secara secara bersama variabel usia, bebesar simpanan, jumlah tanggungan, pengeluaran transportasi dan jumlah kunjungan wisatawan berpengaruh signifikan. Tetapi secara parsial variabel jumlah tanggungan dan jumlah kunjungan wisatawan yang berpengaruh signifikan terhadap pendapatan pekerja sektor informal di sekitar Objek Wisata Jembatan Pedestrian kawasan Objek Wisata Menara Gentala Arasy Kota Jambi.
\end{abstract}

Kata kunci: Pendapatan, Pekerja sektor informal, Objek wisata, Jembatan pedestrian

\section{PENDAHULUAN}

Pembangunan tidak lain merupakan suatu proses perubahan yang berlangsung secara sadar, terencana dan berkelanjutan dengan sasaran utamanya adalah untuk meningkatkan kesejahteraan hidup manusia atau mayarakat suatu bangsa (Arsyad, 2010). Ini berarti bahwa pembangunan merupakan suatu perubahan yang terjadi secara terusmenerus melalui serangkaian kombinasi proses demi mencapai sesuatu yang lebih baik dalam rangka mencapai tujuan nasional suatu bangsa.

Pembangunan ekonomi merupakan suatu proses yang berdampak adanya peningkatan pendapatan perkapita penduduk suatu masyarakat dalam jangka panjang. 
Akan tetapi perekonomian baru dapat dikatakan berkembang apabila pendapatan perkapita menunjukan kecenderungan yang meningkat dalam jangka panjang. Dalam keadaan tertentu misalnya perang, kekacauan politik, kemunduran sector ekspor dll), dapat suatu menyebabkan perekonomian mengalami kemunduran dalam tingkat kegiatan ekonominya.

Pembangunan Provinsi Jambi diarahkan pada usaha untuk menjawab setiap tantangan, yang kedepan akan semakin berat untuk dapat mengangkat Provinsi Jambi menjadi sejajar dengan provinsi-provinsi tetangga lainnya di Sumatera atau dapat mempersempit jurang kesenjangan yang ada pada saat ini.

Dalam pembangunan ekonomi, sector pariwisata merupakan salah satu potensi ekonomi yang harus dikembangkan dalam rangka meningkatkan kesejahteraan masyarakat dan pembanguan daerah. Disamping itu konsep tentang pariwisata mencakup tentang upaya pemberadaan, usaha pariwisata, objek dan daya tarik wisata serta berbagai kegiatan dan jenis usaha.

Perkembangan Pariwisata Provinsi Jambi 2016 ini memuat profil pariwisata, sarana penunjang pariwisata, dan upaya peningkatan pariwisata di Provinsi Jambi. Data yang disajikan diperoleh dari hasil survei lapangan yang dilakukan oleh Badan Pusat Statistik dan survei data sekunder yang berasal dari berbagai Instansi lain. Data yang disajikan mengenai obyek dan daya tarik wisata, kunjungan wisatawan (mancanegara dan nusantara), museum, dan sarana penunjang pariwisata seperti hotel, perhubungan, telekomunikasi, perbankan, rumah sakit, rumah makan/restoran serta sarana penunjang pariwisata lainnya di Provinsi Jambi. Semoga data yang disajikan dalam publikasi ini dapat digunakan sebagai referensi untuk keperluan kepariwisataan dan penelitian atau studi kasus. (BPS, 2016)

Jumlah kunjungan wisatawan mancanegara (wisman) ke jambi yang menginap di hotel berbintang dari Tahun 2011 sampai Tahun 2013 mempunyai kecenderungan menurun, kemeduian trennya naik pada tahun 2014 mencapai 2.114 orang dan kembali berkurang pada Tahun 2015 menjadi 1.086 orang bahkan pada Tahun 2016 hanya 696 orang. Sedangkan jumlah kunjungan wisatwan nusantara (wisnus) dari Tahun 2011 sampai dengan Tahun 2014 mengalami peningkatan dan trennya berkurang di akhir Tahun 2015, yaitu sebanyak 225.954 orang. Pada Tahun 2016 jumlah wisnus kembali naik menjadi 238.701 orang. (BPS, 2016)

Selain banyaknya kunjungan tamu yang tercatat menginap pada hotel berbintang, rata-rata lama menginap selama berada di Jambi juga sangat mempengaruhi rata-rata pengeluarannya. Sehingga secara tidak langsung rata-rata lama menginap akan mempengaruhi penerimaan devisa. Dari tahun 2011 sampai dengan tahun 2015 rata-rata lama menginap wisman dan wisnus di Provinsi Jambi mengalami perubahan signifikan. Rata-rata lama menginap wisnus masih dibawah angka 2, hal ini menunjukkan bahwa rata-rata tamu menginap di hotel maksimal dua malam.

Tahun 2011 rata-rata tamu menginap adalah 1,57 malam dan pada tahun 2015 mengalami kenaikan, yaitu sebesar 1,87 malam. Selama periode 2011-2015 rata-rata lama menginap wisnus terbesar terjadi tahun 2013 (3,31 malam) dan terkecil tahun 2011 (1,57 malam). Sedangkan rata-rata lama menginap untuk wisman cenderung menurun, rata-rata tertinggi terjadi pada tahun 2011 (2,69 malam) dan terendah tahun 2015 (1,91 malam).

Pendapatan merupakan sumber penghasilan seseorang untuk memenuhi kebutuhan sehari - hari dan sangat penting artinya bagi kelangsungan hidup dan penghidupan seseorang secara langsung mau pun tidak langsung (Suroto, 2000).. Pendapatan dapat terdiri dari 3 bentuk yaitu Pendapatan berupa uang, Pendapatan berupa barang Pendapatan lain-lain berupa uang dan barang (Sukriono, 2002).

Pengertian pariwisata adalah perjalanan untuk mencari kesenangan, sekaligus merupakan teori dan praktek berwisata, bisnis menarik, mengakomodasi, dan menghibur wisatawan, dan bisnis jasa tour. Pariwisata bisa antar negara atau domestik. Orang 
dianggap berpariwisata jika bepergian sejauh paling tidak $80 \mathrm{~km}$ dari rumahnya, jika di bawah itu disebut "pelancong" ( Sasrawan, 2013).

Pengelolaan Pariwisata di era zaman sekarang lebih dikenal dengan istilah industry pariwisata, yang dalam pelaksanaanya para wisatawan dibedakan atas beberapa bentuk (Zulkifli, 2002) yaitu: 1).Wisatawan dalam negeri, yang sering dikenal dengan wisnus (wisatawan nusantara atau lokal). 2).Wisatawan luar negeri, yang sering disebut juga wisman (wisatawan mancanegara).

Objek wisata menjadi komoditi yang banyak digunakan oleh suatu Negara. Karena dengan adanya objek wisata maka potensi ekonomi sangat besar, seperti adanya pedagang yang menjajakan berbagai makanan dan minuman, penyediaan alat tranportasi, berbagai jasa-jasa lainnya. Dengan demikian sector pariwisata juga dapat dipengaruhinoleh kondisi ekonomi seperti kondisi moneter, tingkat pendapatan rata-rata penduduk, tingkat daya beli masyarakat, dan lain-lain (Suyitno, 2008).

Pleanggara (2012), dengan judul "Analisis pengaruh jumlah obyek wisata, jumlah wisatawan dan pendapatan perkapita terhadap pendapatan retribusi obyek pariwisata 35 Kabupaten/Kota di Jawa Tengah". Salah satu indikator yang digunakan untuk mengetahui dampak pariwisata terhadap perekonomian daerah, dan juga sebagai salah satu faktor penentu tingginya tingkat perekonomian daerah adalah melalui berkembangnya pendapatan obyek pariwisata yang diterima daerah tersebut.

Salah satu objek wisata yang sedang berkembang saat ini adalah Jembatan Pendestrian yang berada di kawasan Kota Jambi yang merupakan satu kesatuan dengan menera Gentala Arasy yang terletak dikawasan Seberang Kota Jambi yang merupakan ikon terbaru di Kota Jambi dan menjadi salah satu objek wisata yang menarik dan unik. Jembatan Pedestrian merupakan jembatan pejalan kaki. Bentuknya yang menyerupai huruf " $S$ " ini terbentang berkelok-kelok di atas sungai Batanghari kira-kira panjang jembatannya sekitar 530 meter. Jembatan ini dibuat bukan untuk kendaraan, tapi hanya untuk pejalan kaki. Kehadiran jembatan ini memiliki dampak positif dan pengaruh yang sangat signifikan bagi masyarakat Kota Jambi. Dampaknya adalah meningkatkan perekonomian masyarakat, khususnya masyarakat sekitar objek wisata tersebut. Peningkatan ini disebabkan oleh adanya lapangan kerja serta kesempatan untuk memperoleh penambahan hasil usaha bagi jasa-jasa lainnya.

Keberadaan objek wisata jembatan pendestrian dan jambi paradise merupakan objek wisata yang unik. Namun perlu adanya perawatan dan pengelolaan yang baik, sehingga perubahan social ekonomi masyarakat makin meningkat. Dalam hal ini peran masyarakat setempat dan pemerintah sangat diperlukan. Tanpa adanya perhatian khusus objek wisata tersebut akan punah secara perlahan-lahan. Dan dampak bagi para masyarakat yang memiliki usaha di sekitar objek wisata di atas dapat terus meningkatkan pendapatan (keuntungan) diri usaha milik masyarakat tersebut.Penulis mengharapkan bahwa dengan dilakukannya penelitian ini mampu menegaskan faktor apa saja yang memiliki pengaruh yang signifikan terhadap Pendapatan Pekerja Sektor Informal. Dari penjelasan diatas peneliti mengambil judul "Analisis pendapatan pekerja sektor informal disekitar objek wisata jembatan pendestrian Kota Jambi".

\section{METODE}

\section{Jenis data dan penelitian}

Jenis data yang digunakan dalam penelitian ini adalah data Data primer adalah data yang berasal langsung dari responden. Data responden sangat diperlukan untuk mengetahui semua tanggapan mengenai pendapatan pekerja sektor informal yang berjualan di sekitar objek wisata Jembatan Pendestrian di Kota Jambi. Dalam hal ini data yang dibutuhkan seperti hasil dari kuesioner yang telah diisi oleh para pekerja sektor informal di sekitar objek wisata jembatan pendestrian di Kota Jambi. 
Penelitian ini merupakan penelitian dengan metode survey. Penelitian survey merupakan penelitian yang mengumpulkan informasi dari suatu sampel dengan menanyakan melalui angket atau interview supaya nantinya menggambarkan berbagai aspek dari populasi (Faenkel dan Wallen, 2012).

Menurut M. Nazir (2005), pengertian penelitian survei adalah penyelidikan yang dilakukan untuk mendapatkan fakta-fakta dari gejala yang ada dan mencari keteranganketerangan secara faktual baik tentang institusi sosial, ekonomi atau politik dari suatu kelompok atau suatu individu.

\section{Sumber data}

Data-data yang digunakan dalam penelitian ini bersumber dari: a).Badan Pusat Statistik (BPS) Indonesia, b). Wawancara, dan c).Obsevasi d).Kuesioner. Obrservasi merupakan salah satu teknik pengumpulan data yang tidak hanya mengukur sikap dari responden (wawancara dan angket) namun juga dapat digunakan untuk merekam berbagai fenomena yang terjadi (situasi, kondisi). Teknik ini digunakan bila penelitian ditujukan untuk mempelajari perilaku manusia, proses kerja, gejala-gejala alam dan dilakukan pada responden yang tidak terlalu besar. (Tari, 2014).

\section{Metode dan analisis data}

Penelitian ini adalah dengan studi kepustakaan yaitu mengumpulkan berbagai datadata maupun informasi yang berhubungan dalam permasalahan yang diteliti.

\section{Metode dan alat analisis data}

Alat analisis yang digunakan dalam penelitian ini adalah Analisis deskriptif kualitatif dan Analisis Kuantitatif, untuk menjawab rumusan masakah digunakan analisi regresi linear berganda. Adapun bentuk model regresi linear berganda yang menunjukkan hubungan antara variable dependen dan variable independen dalam penelitian ialah sebagai berikut :

$$
Y=\beta_{0}+\beta_{1} X_{1 t}+\beta_{2} X_{2 t}+\beta_{3} X_{3 t}+\beta_{4} X_{4 t}+\beta_{5} X_{5}+e
$$

Keterangan:

$\beta 0 \quad=$ Konstanta

$\beta_{1, \ldots .} \beta_{5}=$ Koefisien

$\mathrm{X} 1=$ Umur responden

$\mathrm{X} 2=$ Besar simpanan

$\mathrm{X} 3=$ Jumlah tanggungan

$\mathrm{X} 4$ = Biaya jumlah tanggungan

X5 = Jumlah kunjungan wisatawan

$\mathrm{e} \quad=$ Secara parsial dan simultan

Sebelum melanjutkan model regresi dalam penelitian ini, ada beberapa langkah yang harus dilakukan, yaitu:

\section{Koefisien determinasi $\left(\mathbf{R}^{2}\right)$}

Koefisien deteminasi $\left(\mathrm{R}^{2}\right)$ mengukur seberapa jauh kemampuan model dalam menerangkan variasi variable indepent. Nilai koefisien determinasi adalah antara nol dan satu.

\section{Uji signifikansi simultan (Uji F)}

Uji statistik F pada dasarnya menunjukkan apakah semua variable independent atau bebas yang dimasukkan dalam model mempunyai pengaruh secara bersama-sama terhadap variable dependen atau terikat.

\section{Uji signifikan individu (Uji t)}

Uji statistic t pada dasarnya menunjukkan seberapa jauh pengaruh satu variable penjelas atau independent secara individual dalam menerangkan variasi variable dependen 


\section{HASIL DAN PEMBAHASAN}

\section{Uji statistik}

Uji statistik terdiri dari pengujian koefisien determinasi $\left(\mathrm{R}^{2}\right)$, pengujian signifikasi simultan (uji F) dan pengujian signifikasi parsial (Uji t).

Dependent Variable: Y

Method: Least Squares

Included observations: 30

Tabel 1. Hasil regresi berganda

\begin{tabular}{|c|c|c|c|c|}
\hline Variable & Coefficient & Std. Error & t-Statistic & Prob. \\
\hline $\mathrm{C}$ & 57006.40 & 50564.48 & 1.127400 & 0.2707 \\
\hline $\mathrm{X} 1$ & -825.8300 & 1670.062 & -0.494491 & 0.6255 \\
\hline $\mathrm{X} 2$ & -0.338299 & 0.449186 & -0.753137 & 0.4587 \\
\hline X3 & 9625.600 & 3656.968 & 2.632126 & 0.0146 \\
\hline $\mathrm{X} 4$ & 0.004973 & 0.014250 & 0.348974 & 0.7302 \\
\hline $\mathrm{X} 5$ & 8705.735 & 3079.553 & 2.826947 & 0.0093 \\
\hline $\mathrm{R}$-squared & 0.821102 & \multicolumn{2}{|l|}{ Mean dependent var } & 33.3 \\
\hline Adjusted R-squared & 0.783832 & \multicolumn{2}{|l|}{ S.D. dependent var } & 38004.84 \\
\hline S.E. of regression & 17669.94 & \multicolumn{2}{|l|}{ Akaike info criterion } & 22.57397 \\
\hline Sum squared resid & $7.49 E+09$ & \multicolumn{2}{|l|}{ Schwarz criterion } & 22.85421 \\
\hline Log likelihood & 332.6096 & \multicolumn{2}{|l|}{ Hannan-Quinn criter. } & 22.66362 \\
\hline F-statistic & 22.03094 & \multicolumn{2}{|l|}{ Durbin-Watson stat } & 1,086040 \\
\hline Prob(F-statistic) & 0.000000 & & & \\
\hline
\end{tabular}

Sumber: Data diolah, 2020

\section{Uji signifikan simultan (Uji F)}

Uji F dilakukan untuk melihat bagaimana pengaruh pendapatan pekerja sektor informal terhadap umur,besar simpanan, jumlah tanggungan, biaya tanggungan, jumlah kunjungan wisatawan. Berdasarkan hasil regresi liner berganda dengan menggunakan eviews pada tabel 5.9 di peroleh $P$ Value dengan probabilitas 0.0000 untuk Uji F simultan. Variabel X1 (umur) X2 (besar simpanan) X3 (jumlah tanggungan) X4 (biaya tanggungan) dan X5 (jumlah wisatawan) secara bersamaan berpengaruh terhadap $\mathrm{Y}=$ pendapatan.

\section{Uji signifikan individu (Uji t)}

Uji t dilakukan untuk mengetahui pengaruh dari masing-masing variabel independen terhadap variabel dependen, Uji t bertujuan untuk melihat seberapa jauh pengaruh individu Umur, Besar Simpanan, Jumlah Tanggungan, Biaya Tanggungan dan Jumlah kunjungan wisatawan.

Berdasarkan hasil estimasi estimasi linear berganda dengan menggunakan pada tabel diketahui bahwa Varibel XI (umur) nilai P - Value sebesar 0.6255, X2 (Besar Simpanan) nilai $\mathrm{P}$ - Value sebesar 0.4587, X4 (Biaya Tanggungan) sebesar 0.7302. Hal ini menunjukan bahwa ketiga variabel tersebut tidak berpengaruh terhadap $\mathrm{Y}=$ Pendapatan, dikarenakan nilai $\mathrm{P}$ - Value lebih besar dari standar signifikan yaitu 0.05.

Sedangkan Variabel X3 (Jumlah Tanggungan) sebesar 0.0146 dan X5 (Jumlah Kunjungan Wisatawan) sebesar 0.0093 menunjukkan bahwa kedua variabel tersebut berpengaruh terhadap $\mathrm{Y}=$ Pendapatan, dikarenakan nilai $\mathrm{P}$ - Value lebih kecil dari standar signifikan yaitu 0.05 . 


\section{Koefesien determinasi $\left(\mathbf{R}^{2}\right)$}

Nilai Adjust R-Squared sebesar 0.783832 yang dapat diartikan bahwa variabel X1 (umur), X2 (Besar Simpanan), X3 (Jumlah Tanggungan), X4 (Biaya Tanggungan) dan X5 (Jumlah Kunjungan wisatawan) mempengaruhi Variabel Y sebesar 78\%.

\section{KESIMPULAN DAN SARAN}

\section{Kesimpulan}

Secara deskriptif dapat dibulatkan bahwa rata-rata kearateristik sosisal ekonomi pekerja sektor informal disekitar Jembatan Pendestrian Kota Jambi lebih baik dari pada sebelum dibangunnya objek wisata Jembatan Pendestrian.

Berdasarkan hasil regresi linear berganda, masing-masing variabel seperti Usia, Besar Simpanan, Jumlah Tanggungan, Biaya Tanggungan dan Jumlah Kunjangan Wisatawan/Hari memiliki hubungan yang erat terhadap pendapatan.

\section{Saran}

Walaupun terjadi perubahan positif karataristik perubahan keadaan sosial ekonomi pekerja sektor informal diharapkan Pemerintah Kota Jambi dapat lebih meningkatkan jumlah dan jenis wisata alam terkait di lokasi sekitar Objek wisata.

Diharapkan kepada pihak terkait dapat memberikan bimbingan dan penyuluhan yang lebih insentif kepada pekerja sektor informal di sekitar objek Jembatan Pendestrian misalnya membuat kios jualan yang bernuansa daerah (Kota Jambi) serta tulisan (simbolsimbol) tradisional Jambi.

\section{DAFTAR PUSTAKA}

Arsyad, Lincolin. (2010). Ekonomi pembangunan. STIE YKPN. Yogyakarta.

Fraenkel, Jack. R., dan Norman E. Wallen. (2012). How to design and evaluate research in education $8^{\text {th }}$ edition. Boston: McGraw-Hill Higher Education.

Nazir, Moh. (2005). Metode penelitian. Ghalia Indonesia: Jakarta.

PH Prihanto, A Bhakti. (2017).Profile of informal sector workers and factors affecting informal sector employment in Jambi Province, Jurnal Perspektif Pembiayaan dan Pembangunan Daerah, 5 (2), 63-70

Sasrawan, Hedi. (2013). Tanah Litosol. Diakses pada https://hedisasrawan. blogspot.co.id/2013/06/tanah-litosol.html, Tanggal 12 Juni 2013, Pukul 12.30 WIB.

Suroto. (2000). Strategi pembangunan dan Perencanaan Perencanaan Kesempatan Kerja. Gajah Mada University: Yogyakarta.

Suyitno. (2008). Modul pengayaan projek pendampingan sma. materi pratikum : klorofil/pigmen fotosintesis. Universitas Negeri Yogyakarta: Yogyakarta.

Tari, Ardiantari. (2014). Teori observasi. Diakses dalam http://mdyantari.blogspot.com/ 2014/06/teori-observasi/, Tanggal 12 Juni 2013, Pukul 12.30 WIB.

Wicaksono. (2011). Pengaruh modal awal, lama usaha, dan jam kerja terhadap pendapatan pedagang kios di Pasar Bintoro Demak. Skripsi. Tidak diterbitkan. Universitas Diponegoro: Semarang.

Y Yusral, J Junaidi, A Bhakti. (2015). Klasifikasi Pertumbuhan, Sektor Basis dan Kompetitif Kota Jambi, Jurnal Perspektif Pembiayaan dan Pembangunan Daerah 2 (4), 209-216 